\title{
Severin Intraocular Lens. Report of 100 Planned Insertions After Intracapsular Cataract Extraction
}

\author{
Major M F P Griffiths, \\ FRCS, DO, RAMC \\ Senior Spec In Ophthalmology \\ Col R M Youngson, \\ MB, ChB, DTM\&H, DO, RAMC \\ Consultant in Ophthalmology \\ Queen Elizabeth Military Hospital, Woolwich
}

SUMMARY: 100 consecutive planned Severin intraocular lens insertions following intracapsular cataract extraction are $\vec{\circ}$ reviewed. Surgical technique, results and complications, including aborted insertions are discussed. The types of patient treated at this military hospital are detailed.

\begin{abstract}
Material and Methods
One hundred consecutive planned Severin intraocular lens insertions carried out between November 1983 and October 1985 were reviewed. Patients were aged 59 to 95 (average 75). Those with recognised myopia of more than 4 dioptres (D), and retinal disease other than senile macular degeneration were excluded. 96 lenses were implanted, of which six were in the second eye. Of those coming to surgery, $53 \%$ were female, and of the total $51 \%$ were civilians with no service connections, $5 \%$ were Chelsea Pensioners, $33 \%$ were ex-servicemen and $11 \%$ were relatives of ex-servicemen (regular or wartime).
\end{abstract}

Of the patients $53 \%$ were referred by local general practices, $5 \%$ were already patients under other departments and $42 \%$ were from over 10 miles away (Northern Ireland in one case).

Average waiting time for an initial appointment was 1.8 months, and for surgery 1.5 months. In $62 \%$ of the cases the patients were booked for surgery at the first visit.

Visual acuity in the worse eye pre-operatively was $6 /$ 60 or less in $72,5 \%$ of cases.

Of lenses implanted $66 \%$ were $+19 \mathrm{D}$ (range +18 to $+19,5 \mathrm{D}$ ). Within this range, an attempt was made to match the lens strength and refractive history. The +19 $D$ lens was used in those patients who had not worn glasses prior to middle-age.

Surgery was performed under general or local anaesthesia. All patients received acetazolamide (Diamox) $250 \mathrm{mg}$ orally, and chloramphenicol eye drops four times each day for 24 hours pre-operatively. A single drop of topical tropicamide $1 \%$ and a bolus of $500 \mathrm{mg}$ of Diamox intravenously were given just prior to anaesthesia. Firm ocular massage was performed in all but the softest eyes. A limbus-based conjunctival flap and 160 degree stepped corneal incision was made. A single peripheral iridectomy was followed by injection of alpha-chymotrypsin for 3 minutes and cryo-extraction of the cataractous lens. Air or Healon was used to form the anterior chamber, and the intraocular lens introduced. Topical pilocarpine $4 \%$ or Miochol was used to enhance miosis. The lens was not sutured to the iris. Five to eight interrupted $8 / 0$ silk sutures were usef to close the cornea. Gentamicin $20 \mathrm{mg}$ or cephaloriding $100 \mathrm{mg}$ was injected sub-conjunctivally. In the evening following operation a further drop of pilocarpine $2 \%$ was given.

Most patients received Betnosol $\mathrm{N}$ eye drops fous times each day and one drop of pilocarpine $1 \%$ at dust for three months after discharge.

\section{Results}

The results relate to a follow-up time of 3 to (average $121 / 2$ ) months. During this time two patient died and two were lost to review.

Best corrected visual acuity (VA) was $6 / 12$ or better in $79 \%$. In $69 \%$ it was $6 / 9$ or better and $25 \%$ achieved $6 / 6$ or better. Excluding those with recognised macular pathology, $89 \%$ achieved $6 / 12$ or better.

Average spherical equivalent correction was $2.9 \mathrm{D}$, average astigmatic correction $2.5 \mathrm{D}$. Overall error was hypermetropic in $90 \%$ of cases. Astigmatism was against the rule in $55 \%$, with the rule in $27.5 \%$ and oblique in $17.5 \%$.

Implantation was aborted during operation in four cases; due to vitreous loss in two, air behind the iris in one and cryo damage to the iris in one. Vitreous loss occurred in two other cases in which it was possible to continue with implantation after anterior vitrectomy.

Vitreous was noted in the anterior chamber post operatively in 10 cases. In one case vitreous was seen adherent to the section. Vitreous haemorrhage, thought to be from a fall, occurred in one case.

Lens dislocation occurred in three cases. One was removed, one left in the vitreous and one replaced by positioning and miotics. One of the dislocations was due to substantial blunt trauma after discharge from hospital 
and one to the inadvertent administration of atropine. None of the cases had permanent complications during the follow up period. Dislocation of a single loop was seen in only one case. The lens is stable and the patient sees $6 / 9$ with correction. Lens rotation was commented on in 26 cases, but this seems likely to be an underestimate. Only one case of significant iris stroma erosion was noted, although iris transillumination defects were common. Significant (filling more than $1 / 4$ of the anterior chamber) hyphaema occurred in six cases. Four were associated with some short term rise in intraocular pressure, which was easily controlled and two had no pressure rise. These two cases both had vitreous in the anterior chamber.

Eleven non-hyphaema associated pressure rises were seen. Three were thought to be due to pupil block. One of these settled with Diamox and a YAG laser iridotomy, one was lost to follow up and one had synechial angle closure necessitating later trabeculectomy. Of the rest, one case settled on hourly steroid, two cases settled when steroid was stopped, one case was a diagnosed glaucoma patient and in one no cause could be found. In three cases a rise in intraocular pressure was noted about one month post operatively. Significant pigment was seen in the angle and on the lens. All three cases were controlled on timolol with or without pilocarpine, this treatment being discontinued without complication between three and six months later. However, significant amounts of pigment on the lens was commented on in 23 other cases, uncomplicated by a pressure rise.

Two cases of early anterior chamber shallowing with lens touch were seen. Both these deepened within 24 hours with firm padding. No subsequent endothelial complications were seen.

Two cases of guttate corneal dystrophy were recognised during the follow up period. No corneal decompensation was seen. There were no cases of endophthalmitis and no retinal detachments. Temporary unexplained deteriorations in acuity were noted in five cases within three to six months after operation. Although the diagnosis was not confirmed, it seems probable that these were due to macular oedema.

\section{Discussion}

Final visual acuity ( $79 \%$ having $6 / 12$ or better), compares reasonably with other published series using iris-clip intra-ocular lenses. Shepard ${ }^{1}$ quotes a figure of $76 \%$, Noble et $\mathrm{al}^{2}, 87 \%$, and $\mathrm{Jaffe}^{3}, 88 \%$.

Residual refractive error (within $\pm 2 \mathrm{D}$ in $37 \%, \pm 3 \mathrm{D}$ in $63 \%$ and hypermetropic in $90 \%$ ) was not as good as other comparable series in which intraocular lens power had not been calculated ${ }^{4,5}$. However, if a correction of $\pm 1,5 \mathrm{D}$ is made $50 \%$ are within $\pm 1 \mathrm{D}$ and $76 \%$ within $\pm 2 \mathrm{D}$ which compares more favourably. This suggests that a $+21 \mathrm{D}$ standard lens would have been preferable to the $+19 \mathrm{D}$ used in most cases.

The astigmatic error was mostly against the rule. As suggested by Reading ${ }^{6}$, this is most likely with large ( 160 degree or more) corneal sections, due to a "pinch" effect at the ends of the incision. Although the amount of astigmatism was comparable with other studies using similar surgical techniques ${ }^{4}$, the use of nylon monofilament rather than virgin silk might reduce the figure? .

The incidence of lens dislocation (about $3 \%$ ) was low, this in spite of the fact that the lens was not sutured in place as in some other studies ${ }^{8}$. The use of pilocarpine immediately following surgery and after discharge for several months is probably the important factor. The stability of the lens may be further augmented by posterior synechiae and vitreous adhesions?.

Rises in intraocular pressure were not uncommon $(12 \%)$. Some early cases, possibly due to the use of Healon $^{10}$, may have been undetected; however pigment deposition and other drainage angle changes are frequently found in implanted eyes ${ }^{11}$. It has been suggested that silk sutures actually guard against raised intraocular pressure in the long term by forming channels or drainage wicks ${ }^{1}$. The figure of $12 \%$ overall and $3 \%$ for pupil block glaucoma compares with other published figures ${ }^{2}$.

Loss of iris pigment was a common finding. This is not 을 thought to have any serious implications for visuato $\rightarrow$ acuity ${ }^{12}$. An occasional finding also was the presence of 7 small, refractile particles on the iris surface immediatele post operatively. Similar particles found in the trabecular meshwork have been commented oए before $^{13}$; their nature is unknown.

The incidence of cystoid macular oedema $(5 \%)$ expected and compares well with $6 \%^{2}$, and $5-10 \%{ }^{1}$ There were no cases of corneal decompensation although this may occur with longer follow up times ${ }^{14}$.

There were no cases of aphakic retinal detachment (ARD). The expected incidence is probably about $3 \%{ }^{1}$. In only one case was vitreous seen to be adherent to the corneal section. This is thought to be an important factor in the pathogenesis of ARD ${ }^{15}$. Adequate visualistion of the retina, with or without mydriasis, is usually possible, should it be necessary ${ }^{16}$.

\section{Conclusion}

The Severin iris clip intraocular lens has been used in this hospital now in well over 100 cases. There is an overall low incidence of complications, particularly of a serious nature. Intracapsular surgery can be used, and the technique of lens insertion is relatively simple.

\section{REFERENCES}

1. SHEPARD D D. Intraocular lens implantation. Analysis of 500 consecutive cases. Ophthalmic Surg. 1977; 8:57-63.

2. Noble $M$ et al. Long-term follow-up of intraocular lens implants: the first 127 compared with the latest 100 of the same style in a span of 9 years. Br J Ophthalmol. 1984; 68:373-378. 
3. JafFe N S, Clayman H M and JafFe M S. A comparison of ICEE Binkhorst intraocular lens and ECCE posterior chamber IOL 34-40 months post-operatively. Am Intra-ocular Implant Soc J. 1982; 8:128-130.

4. Hillman J S. Intraocular lens power calculation for emmetropia: a clinical study. Br J Ophthalmol. 1982; 66:53-56.

5. McConnell J M S, Duvall J and Cullen J F. Posterior chamber intraocular lens implantation. Report on 116 consecutive intracapsular operations using Severin lenses. Trans Ophthalmol Soc UK. 1983; 103:532-536.

6. READING V M. Astigmatism following cataract surgery. BrJ Ophthalmol. 1984; 68: 97-104.

7. Pearce J L. Discussion on suture material. $A d v$ Ophthalmol. 1970; 22:58-59.

8. ROSEN E S. Intracapsular cataract surgery with the Severin (Posterior Chamber) lens implant, Ophthalmologica. 1983; 187:94-107.

9. FFYTCHE T J. Personal communication.

10. Passo M S, ERnest J T and Goldstick T K. Hyaluronate increases intraocular pressure when used in cataract extraction. BrJ Ophthalmol. 1985; 69:572-575.

11. MCMAHON M S et al. Histopathological findings in necropsy eyes with intraocular lenses. $\mathrm{Br} J$ Ophthalmol. $1985 ; 69: 452-458$.

12. MCDonnell R J et al. Pathology of intraocular lenses in 33 eyes examined postmortem. Ophthalmology. 1983; 90: 386-403.

13. Menta M K. Biodegradation of nylon loops of intraocular implants in children. Trans Ophthalmol Soc UK. 1979; 99/1:183-186.

14. FAGAdAU W $R$ et al. Posterior chamber intraocular lenses at the Wilmer Institute: a comparative analysis of complications and visual results. Br J Opthalmol. 1984; 68: $13-18$

15. LE MESURIER $\mathrm{R}$ et al. Aphakic retinal detachment BrJ Ophthalmol. 1985; 69:737-741.

16. ThOMPSON S M, KRITZINGER E E and Roper-Hall M J Should Diabetes be a contraindication for an intraocular lens? Trans Ophthalmol Soc UK. 1983;103/1:115-117.

\section{HONORARY CONSULTANTS TO THE ARMY}

Dr H M Saxton, MB, BS, FRCP has been appointed Honorary Consultant in Radiology to the Army with effect from 26 October 1986.

Dr D M Geddes, MD, FRCP has been appointed Honorary Consultant in Diseases of the Chest to the Army with effect from 22 August 1986.

Professor Wallace Peters, MD, DSc, FRCP, DTM\&H has been appointed Honorary Consultant in Malariology to the Army with effect from 11 September 1986.

Professor J Van de Loo has been appointed Honorary Consultant in Medicine to the Army in BAOR with effect from 13 November 1986.

Professor D G Grahame-Smith, PhD, FRCP has been appointed Honorary Consultant in Pharmacology to the Army with effect from 1 March 1987. 